\title{
Multi tyrosine kinase inhibitor dasatinib as novel cause of severe pre-capillary pulmonary hypertension?
}

\author{
Jan K Hennigs ${ }^{1,2,3}$, Gunhild Keller², Hans Jörg Baumann ${ }^{1,2}$, Friedemann Honecker ${ }^{2}$, Stefan Kluge ${ }^{1,3}$, \\ Carsten Bokemeyer ${ }^{1,2}$, Tim H Brümmendorf ${ }^{2}$ and Hans Klose ${ }^{1,2^{*}}$
}

\begin{abstract}
Background: Pulmonary hypertension (PH) is a life-threatening disease with poor prognosis. Encouraging efforts have been made to target the main vasoproliferative aspects of the disease. Promising emerging therapeutics are tyrosine kinase inhibitors such as imatinib.

Case presentation: Here, we discuss the relevance of previously published cases and add another wellcharacterised patient who developed pre-capillary PH under long-term therapy with the multi-tyrosine kinase inhibitor dasatinib approved for therapy of chronic myeloic leukaemia (CML) and Philadelphia chromosome positive acute lymphocytic leukaemia (mean time of all patients on dasatinib: 26 months). Hence, we discuss the possibility of dasatinib itself causing PH after long-term therapy and turn specialist's attention to this possible severe side effect.

At present, the true incidence of dasatinib-associated $\mathrm{PH}$ remains illusive and systematic data regarding haemodynamics are missing.

Conclusion: We therefore recommend systematic screening of dasatinib-treated patients for pulmonary hypertension and subsequent collection of haemodynamic data.
\end{abstract}

Keywords: Pulmonary hypertension, drug induced, antiproliferative therapy, leukaemia, side effects

\section{Background}

Pulmonary hypertension $(\mathrm{PH})$ is a severe and progressive, mainly vasoproliferative disease characterised by increased pulmonary artery pressure and vascular resistance eventually leading to right heart failure and death [1]. Different drugs have been identified to be causative of $\mathrm{PH}$ such as anorectic drugs which gained notoriety in the 1970s [2].

Dasatinib is a multi tyrosine kinase inhibitor approved for first and second line therapy of chronic myeloic leukaemia (CML) and Philadelphia chromosome positive acute lymphocytic leukaemia $[3,4]$.

During the last months there have been two reports connecting dasatinib with the development of PAH

\footnotetext{
* Correspondence: klose@uke.uni-hamburg.de

${ }^{1}$ Centre for Pulmonary Hypertension, University Medical Centre Hamburg

Eppendorf, 20246 Hamburg, Germany

Full list of author information is available at the end of the article
}

$[5,6]$. Alarmingly, another patient was referred to our centre presenting with severe pre-capillary $\mathrm{PH}$ under dasatinib therapy.

Here, we report on this case and would like to turn attention to this possible severe side effect of dasatinib.

\section{Case presentation}

A 70-year old male with chronic phase CML diagnosed in 1996 was changed to dasatinib therapy due to subsequent haematological progress under hydroxyurea combined with interferon alpha (1996-2002) and imatinib (2002-2004: 400 mg/day, 2004-2005: 800 mg/d). Dasatinib treatment with a dose of $70 \mathrm{mg}$ bid was applied for 32 months. Side effects during this period were minor as the medication was generally tolerated well.

However, suddenly the patient developed tachy-dyspnea (25/min), transsudative, non-malignant pleural effusions (glucose $116 \mathrm{mg} / \mathrm{dl}$; lactate dehydrogenase $188 \mathrm{IU} / \mathrm{ml}$ of 
effusions, serum lactate dehydrogenase $1073 \mathrm{IU} / \mathrm{ml}$; protein content of effusions $31 \mathrm{~g} / \mathrm{l}$, serum protein content $67 \mathrm{~g} / \mathrm{l}$ ) and fatigue increasing within a few weeks.

Echocardiography showed highly increased right ventricular systolic pressure (RVSP) of $73 \mathrm{~mm} \mathrm{Hg}$. Invasive haemodynamic evaluation confirmed severe pre-capillary $\mathrm{PH}$ with consecutive right heart failure (details on prognostic factors and haemodynamics listed in Table 1). Clinically, the patient was assigned to WHO/NYHA functional class IV.

As other underlying pathophysiological reasons were ruled out by serological tests, chest $\mathrm{CT}$, scintigraphy of the lung and abdominal ultrasound, dasatinib was consequently discontinued. Normal wedge pressures at right heart catheterisation also excluded tyrosine kinase inhibitor-induced cardiomyopathy or other left heart diseases as possible underlying pathologies.

After discontinuation of dasatinib medication low-dose $\mathrm{PAH}$-specific therapy with vasodilative phosphodiesterase- $\mathrm{V}$ inhibitor sildenafil $(3 \times 20 \mathrm{mg})$ was initiated. Acute symptoms relieved within days.

During the following 10 months prognostic parameters such as the N-terminal fragment of pro brainnatriuretic peptide (NT-proBNP), 6-minute walking distance (6MWD), RVSP, pulmonary artery mean pressure $\left(\mathrm{PAP}_{\text {mean }}\right)$ and pulmonary vascular resistance (PVR) improved significantly (see Table 1). Additionally, the patient's subjective well-being advanced decisively which was also reflected by a functional class improvement to NYHA II (Figure 1).

\section{Does dasatinib itself trigger pre-capillary PH?}

Pulmonary complications of dasatinib therapy have been reported ranging from pleural effusions to lung parenchymal affections [7]. In particular, pleural effusions caused by dasatinib, which are mostly exsudative due to clonal expansion of natural killer $\mathrm{T}$ cells, are well

\section{Table 1 Haemodynamic and prognostic data}

\begin{tabular}{|c|c|c|c|c|c|}
\hline \multirow[b]{2}{*}{ Month: } & \multirow{2}{*}{$\begin{array}{c}\text { Time of presentation } \\
\text { (/w dasatinib) }\end{array}$} & \multicolumn{4}{|c|}{$\begin{array}{l}\text { Time course under } \\
\text { sildenafil (w/o dasatinib) }\end{array}$} \\
\hline & & +1 & +3 & +5 & +7 \\
\hline RVSP [mm Hg] & 73 & 51 & - & 17 & - \\
\hline $\mathrm{PAP}_{\text {mean }}[\mathrm{mm} \mathrm{Hg}]$ & 52 & - & - & - & 40 \\
\hline PVR $\left[\mathrm{dyn} * \mathrm{~s} / \mathrm{cm}^{-5}\right]$ & 1250 & - & - & - & 356 \\
\hline $\mathrm{CO}[\mathrm{I} / \mathrm{min}]$ & 1.7 & - & - & - & 4.7 \\
\hline $\mathrm{HR}$ [/min] & 105 & - & - & - & 85 \\
\hline proBNP [ng/l] & 27055 & 3037 & 1334 & 2076 & - \\
\hline 6MWD [m] & 0 & 308 & 458 & - & - \\
\hline WHO/NYHA FC & IV & $\|$ & $|/| \mid$ & $\|$ & $\|$ \\
\hline
\end{tabular}

RVSP: right ventricular systolic pressure; PAPmean: mean pulmonary artery pressure; PVR: pulmonary vascular resistance; CO: cardiac output; HR: heart rate; proBNP: brain natriuretic peptide propeptide; 6MWD: 6-minute walk distance; WHO/NYHA FC: World Health Organization/New York Heart Association functional class. recognised and have been documented in various studies $[3,7,8]$. In addition to the EMEA data set [3], in a retrospective analysis of 138 patients receiving dasatinib in once or twice daily treatment schedules, pleural effusions of any grade were detected in $35 \%$ of the complete study population comprising chronic phase, accelerated phase and blast crisis [8].

Statistically significant, dose-dependent increase in RVSP was reported in a subgroup of 18 patients and dasatinib cessation led to normalisation of RVSP in 10 patients [8]. Dyspnoea, nausea, fatigue and oedema unspecific yet classical symptoms found in $\mathrm{PH}$ - are among the most frequently observed unwanted dasatinib effects. Up to now, the extent of dasatinib-associated pre-capillary $\mathrm{PH}$ in contribution to these symptoms remains illusive since data regarding haemodynamics are lacking. However, all three detailed cases with dasatinibrelated pre-capillary $\mathrm{PH}$ developed after a 2-year period of treatment (Figure 1C).

Our findings in combination with the two other published cases suggest a yet unknown association of precapillary PH with dasatinib [9]. Therefore, our patient was categorised into Dana Point class 1.3 that resembles drug-induced pulmonary arterial hypertension (PAH, [10]). Dana Point I represents the only class where PAH-specific drugs are labelled for. Hence PAH-specific therapy with low-dose sildenafil was started.

Dana Point class V, on the other side, combines all multifactorial or uncertain causes of $\mathrm{PH}$ and it explicitly includes chronic myeloproliferative diseases. Nevertheless, in this case connection of $\mathrm{PH}$ with myeloproliferative disease is also unlikely since, firstly, the CML was stable under dasatinib therapy for almost three years without acceleration until the end of dasatinib therapy. Secondly, a recent report showed a preferential association of myeloproliferative disease-associated $\mathrm{PH}$ with chronic thromboembolism [11], which was ruled out in our patient by CT scans and V/Q scintigraphy. In such case the use of sildenafil would have been off-label.

Taking into consideration that pleural effusions are found rarely in pre-capillary pulmonary hypertension another differential diagnosis has to be mentioned: pulmonary veno-occlusive disease (PVOD). PVOD, again, seems to be unlikely since it typically presents as nonresponsive $\mathrm{PH}$ [12]. However, symptoms and RVSP of our patient rapidly improved after discontinuation of dasatinib and initiation of sildenafil therapy. Additionally, typical signs of PVOD such as ground glass opacity and septal thickening in CT scans or crackles and clubbing on examination [10] were absent in the presented case.

Most interestingly, although dasatinib also inhibits the platelet-derived growth factor receptor (PDGFR) pathway there may be a contrary effect on proliferative 

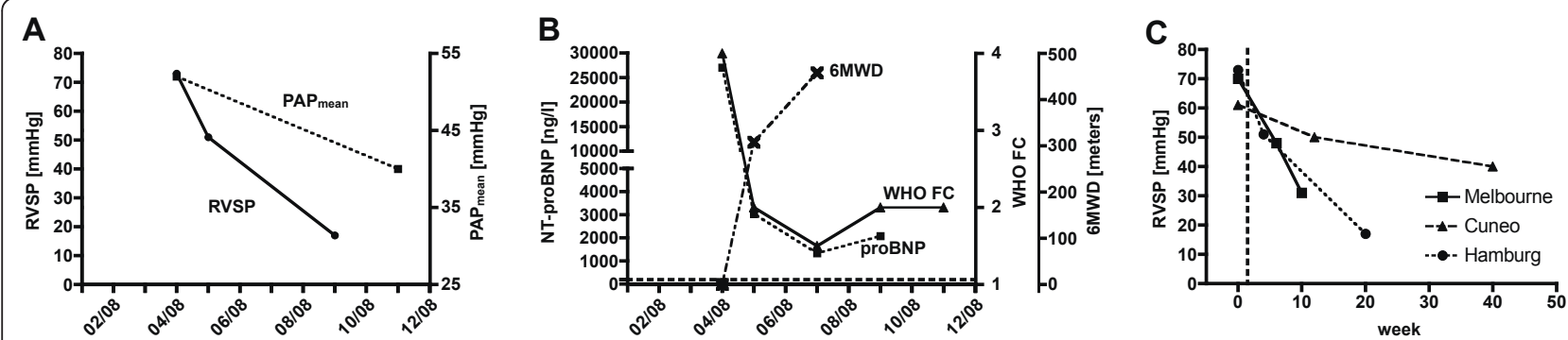

Figure 1 Haemodynamics and prognosis factors of dasatinib-associated PAH. Time courses of haemodynamics (Right ventricular systolic pressure, RVSP and mean pulmonary artery pressure, PAPmean, A) as well as exercise capacity (6MWD), WHO functional class and concentration of NT-proBNP (B) of the Hamburg patient are shown. Dashed horizontal line in (B) represents upper normal limit of NT-proBNP concentration $(<197 \mathrm{ng} / \mathrm{l})$. RVSP time courses of all three dasatinib-associated PH cases characterised so far are shown in (C). Vertical dashed line represents time of discontinuation of dasatinib treatment.

aspects of PAH compared to imatinib which has been shown to be an effective treatment improving $\mathrm{PAH}$ and animal survival as well as reversing pulmonary remodelling in rodent model systems, a series of case reports and a phase II trial [13-18]. Hence, a prospective randomised safety and efficacy trial is currently ongoing (IMPRES, ClinicalTrials.gov: NCT00902174).

As key mechanisms, imatinib reversed overexpression and increased phosphorylation of PDGFR $\beta$ in pulmonary arteries from rat models of pulmonary hypertension, inhibited PDGFR-related ERK1/2 activation in lungs of these animals thereby suppressing rat pulmonary artery smooth muscle cell (PA-SMC) proliferation and inducing PA-SMC apoptosis [13].

While dasatinib inhibits Bcr-Abl at significantly lower inhibitory concentrations $\left(\mathrm{IC}_{50}\right)$ as compared to imatinib, its effect on c-kit and PDGFR are rather similar. In addition, however, and different from imatinib, dasatinib also inhibits the SRC family of kinases [19]. Whether this aspect of the compound is causally related to $\mathrm{PH}$ development remains unclear.

\section{Conclusion}

There are emerging data that dasatinib could trigger drugassociated pre-capillary pulmonary hypertension. We therefore recommend the systematic screening and collection of haemodynamic data of dasatinib-treated patients.

\section{Consent}

Written informed consent was obtained from the patient for publication of this case report. A copy of the written consent is available for review by the Editor-in-Chief of this journal.

\section{Author details}

${ }^{1}$ Centre for Pulmonary Hypertension, University Medical Centre Hamburg Eppendorf, 20246 Hamburg, Germany. ${ }^{2}$ Department of Internal Medicine II Oncology, Haematology, BMT and Pneumology, University Medical Centre Hamburg - Eppendorf, 20246 Hamburg, Germany. ${ }^{3}$ Department of Critical
Care Medicine, University Medical Centre Hamburg - Eppendorf, 20246 Hamburg, Germany.

\section{Authors' contributions}

$F H, H J B, H K, T H B$ and $C B$ were involved in diagnostics and treatment of the patient. JKH, GK, HJB, SK and HK drafted the manuscript. All authors contributed to writing and editing the manuscript for important intellectual content. All authors read and approved the final manuscript.

\section{Competing interests}

$C B$ and THB have received travel grants, presentation fees and research grants form Bristol Myers Squibb. All other authors state no competing interests.

Received: 2 November 2010 Accepted: 23 May 2011

Published: 23 May 2011

\section{References}

1. Humbert M, Sitbon O, Simonneau G: Treatment of pulmonary arterial hypertension. N Engl J Med 2004, 351(14):1425-1436.

2. Michelakis ED, Weir EK: Anorectic drugs and pulmonary hypertension from the bedside to the bench. Am J Med Sci 2001, 321(4):292-299.

3. EMEA: Sprycel - Scientific Discussion. European Public Assessment Report (EPAR) 2008, (EMEA/H/C/709).

4. FDA: Dasatinib - Pharmacogenomic Information: Indications and Usage. 2010.

5. Rasheed W, Flaim B, Seymour JF: Reversible severe pulmonary hypertension secondary to dasatinib in a patient with chronic myeloid leukemia. Leuk Res 2009, 33(6):861-864.

6. Mattei D, Feola M, Orzan F, Mordini N, Rapezzi D, Gallamini A: Reversible dasatinib-induced pulmonary arterial hypertension and right ventricle failure in a previously allografted CML patient. Bone Marrow Transplant 2009, 43(12):967-968.

7. Bergeron A, Rea D, Levy V, Picard C, Meignin V, Tamburini J, BruzzoniGiovanelli H, Calvo F, Tazi A, Rousselot P: Lung abnormalities after dasatinib treatment for chronic myeloid leukemia: a case series. Am J Respir Crit Care Med 2007, 176(8):814-818.

8. Quintás-Cardama A, Kantarjian H, O'brien S, Borthakur G, Bruzzi J, Munden $\mathrm{R}$, Cortes J: Pleural effusion in patients with chronic myelogenous leukemia treated with dasatinib after imatinib failure. $J$ Clin Oncol 2007, 25(25):3908-3914.

9. Galie N, Hoeper MM, Humbert M, Torbicki A, Vachiery JL, Barbera JA, Beghetti M, Corris P, Gaine S, Gibbs JS, et al: Guidelines for the diagnosis and treatment of pulmonary hypertension. Eur Respir J 2009, 34(6):1219-1263.

10. Simonneau G, Robbins IM, Beghetti M, Channick RN, Delcroix M, Denton CP, Elliott CG, Gaine SP, Gladwin MT, Jing ZC, et al: Updated clinical classification of pulmonary hypertension. J Am Coll Cardiol 2009, 54(1 Suppl):S43-54.

11. Guilpain $P$, Montani D, Damaj $G$, Achouh L, Lefrère F, Le Pavec J, MarfaingKoka A, Dartevelle P, Simonneau G, Humbert M, et al: Pulmonary 
hypertension associated with myeloproliferative disorders: a retrospective study of ten cases. Respiration 2008, 76(3):295-302.

12. Harch S, Whitford H, McLean C: Failure of medical therapy in pulmonary arterial hypertension. Is there an alternative diagnosis? Chest 2009, 135(6):1462-1469.

13. Schermuly RT, Dony E, Ghofrani HA, Pullamsetti S, Savai R, Roth M, Sydykov A, Lai YJ, Weissmann N, Seeger W, et al: Reversal of experimental pulmonary hypertension by PDGF inhibition. J Clin Invest 2005, 115(10):2811-2821.

14. Ghofrani HA, Seeger W, Grimminger F: Imatinib for the treatment of pulmonary arterial hypertension. N Engl J Med 2005, 353(13):1412-1413.

15. Patterson KC, Weissmann A, Ahmadi T, Farber HW: Imatinib mesylate in the treatment of refractory idiopathic pulmonary arterial hypertension. Ann Intern Med 2006, 145(2):152-153.

16. Souza R, Sitbon $\mathrm{O}$, Parent $\mathrm{F}$, Simonneau G, Humbert M: Long term imatinib treatment in pulmonary arterial hypertension. Thorax 2006, 61(8):736.

17. Grinnan DC, Fairman P, Pinson J: Recurrence of severe pulmonary hypertension following the removal of a lung allograft. Chest 2007, 132(6):2057-2058, author reply 2058

18. Ghofrani HA, Morrell NW, Hoeper MM, Olschewski H, Peacock AJ, Barst RJ, Shapiro S, Golpon H, Toshner M, Grimminger F, et al: Imatinib in pulmonary arterial hypertension patients with inadequate response to established therapy. Am J Respir Crit Care Med 2010, 182(9):1171-1177.

19. Rix U, Hantschel O, Dürnberger G, Remsing Rix LL, Planyavsky M, Fernbach NV, Kaupe I, Bennett KL, Valent P, Colinge J, et al: Chemical proteomic profiles of the BCR-ABL inhibitors imatinib, nilotinib, and dasatinib reveal novel kinase and nonkinase targets. Blood 2007, 110(12):4055-4063.

\section{Pre-publication history}

The pre-publication history for this paper can be accessed here: http://www.biomedcentral.com/1471-2466/11/30/prepub

doi:10.1186/1471-2466-11-30

Cite this article as: Hennigs et al:: Multi tyrosine kinase inhibitor dasatinib as novel cause of severe pre-capillary pulmonary hypertension? BMC Pulmonary Medicine 2011 11:30.

\section{Submit your next manuscript to BioMed Central and take full advantage of:}

- Convenient online submission

- Thorough peer review

- No space constraints or color figure charges

- Immediate publication on acceptance

- Inclusion in PubMed, CAS, Scopus and Google Scholar

- Research which is freely available for redistribution

Submit your manuscript at www.biomedcentral.com/submit 